\title{
Premature Adrenarche
}

National Cancer Institute

\section{Source}

National Cancer Institute. Premature Adrenarche. NCI Thesaurus. Code C113337.

Premature onset of adrenal androgen-mediated secondary sexual characteristics. 